\title{
perifèria
}

Número 9, desembre 2008

www. periferia. name

\section{Salut i malaltia: una nova realitat. Aproximació etnogràfica a partir del servei d'urgències de l'Hospital de Sabadell}

\author{
Rita Prat Caballol ${ }^{1}$ - Departament Antropologia social i cultural (UAB)
}

\section{Resum}

Els últims decennis, i a conseqüència dels grans canvis tecnològics, les concepcions i percepcions sobre la salut i la malaltia, així com les pràctiques de tot allò que té a veure amb aquests aspectes, han canviat; s'hi han introduït nous elements i se n'han deixat d'altres pel camí.

Aquest article sorgeix del treball realitzat per la tesina del Màster en Antropologia. És una aproximació a la utilització dels serveis d'urgències hospitalaris. Es pregunta què porta a les persones a acudir-hi, tenint en compte com s'entenen i què representen els conceptes de salut i malaltia, els d'urgència i de gravetat, quines pràctiques es realitzen quan un es posa malalt i quines passes se segueixen per la curació. Es tracta d'un treball antropològic sobre la salut i la malaltia que té en compte aspectes mèdics.

Paraules clau: concepció, percepció, salut, malaltia, urgència, gravetat.

\begin{abstract}
In the last decades, as a consequence of the important technological leap, the conceptions and perceptions about health and disease, and also the customs related with these concepts, have changed; new factors have been introduced and others discarded.

This article comes from the research made concerning the dissertation of my Master in Anthropology. It is an approach to the usage of the hospital urgency services. It questions what brings people to make use of them, having into account how are understood and what represent the concepts of health and disease, urgency and severity, what is done when someone becomes ill and which steps are followed towards the healing. It is an anthropological work about health and disease taking into account medical aspects.
\end{abstract}

Key words: conception, perception, health, disease, urgency, severity.

\footnotetext{
${ }^{1}$ Enviar correspondència a: ritaprat@gmail.com, rita.prat@campus.uab.cat
} 


\section{perifèria}

Número 9, desembre 2008

www.periferia. name

\section{I ntroducció}

La salut i la malaltia formen part de la naturalesa i de la vida dels éssers vius, també de les persones. Però a ningú se li escapa que també són construccions socioculturals que van prenent formes diverses en cada moment i context històric diferent. Al Ilarg dels últims decennis la revolució que hi ha hagut en tots els camps de la ciència, també en el de la biomedicina, han comportat canvis importants en la sanitat i segurament una manera diferent d'entendre la salut i la malaltia dins la nostra societat, que implica també canvis en les seves pràctiques.

El present article és fruit de la investigació realitzada en persones que havien acudit al servei d'urgències de l'Hospital de Sabadell. Vaig realitzar una entrevista enregistrada a 26 persones, 13 homes i 13 dones, d'edats compreses entre els 24 i 79 anys d'edat, que visquessin a la ciutat de Sabadell i haguessin nascut a l'Estat Espanyol. També vaig dur a terme sessions d'observació i de vàries conversacions informals en les sales d'espera del servei d'urgències i amb alguns professionals sanitaris.

\section{Justificació de la investigació}

En els últims anys ha existit una utilització creixent de tots els serveis sanitaris, i de manera especial els serveis d'urgències hospitalàries (SUH), per iniciativa pròpia de la població. Segons Aranaz Andrés et al. (2006), s'ha passat de 375 visites per cada mil habitants l'any 1993 a superar les 500 l'any 2000, tenint en compte que aquestes dades ja venien creixent de forma progressiva amb anterioritat a l'any 1993 i segueixen creixent des d'aleshores, fins a contribuir en l'actualitat de manera directa al col-lapse i massificació gairebé permanent d'aquests serveis. S'han realitzat molts estudis per determinar el percentatge d'assistències "no justificades" en els SUH, i les dades són diverses segons les variables que s'han tingut en compte. Aquestes oscil-len entre el $40 \%$ i el $80 \%$ de les assistències efectuades, segons Ochoa et al.(2000) i Gómez Jiménez (2006), entre molts altres estudis. Però aquests estudis provenen del camp de la biomedicina i han buscat causes principalment organitzatives i/o de deficiències del sistema sanitari, o bé responsabilitzant als propis usuaris: per tenir pocs coneixements en l'oferta 


\section{perifèria}

Número 9, desembre 2008

www. periferia. name

sanitària o culpabilitzant-los en aspectes psicoemocionals, donant poca importància a elements que tinguin a veure amb el camp social. En el nostre país existeixen pocs estudis que ho expliquin des d'una vessant antropològica, més holística, en la qual es tinguin en compte altres aspectes que tinguin arrels socials.

Per tant, la justificació del treball realitzat és la de donar explicació a aquesta problemàtica que es genera, donades les repercussions que té tant en les persones usuàries de l'atenció assistencial sanitària com en els professionals que han d'atendre a aquestes persones.

\section{Les concepcions i percepcions de la salut i la malaltia}

La malaltia és un estat experimentat per les persones que ens produeix malestar i al qual s'hi vol donar solució o resposta. El concepte de salut ha tingut múltiples definicions, però la més coneguda i que va marcar un punt d'inflexió és la que va realitzar la Carta Fundacional de la OMS I'any 1948: “La salud es un estado de completo bienestar físico, mental y social, y no solamente la ausencia de afecciones y enfermedades. La posesión del mejor estado de salud que se es capaz de conseguir constituye uno de los derechos fundamentales de todo ser humano, cualquiera que sea su raza, religión, ideología política y condición económico social". Definició que alguns ja la donen per superada, però a la realitat encara avui no està del tot assolida, ja que el nostre sistema sanitari contempla la salut en base principalment a la salut física; els aspectes mentals, en part, queden en un segon terme, i els socials estan fora de la contemplació del sistema.

Per definir salut i malaltia s'utilitzen molts conceptes, però n'hi ha uns que els han fet servir la majoria dels entrevistats, són els que se'ls dóna la màxima importància. La salut la descriuen com: "és el principal", "és tot", "és el millor que pots tenir". I la malaltia com: "és el pitjor", "és passar-ho malament". Molt sovint encara, salut i malaltia han estat definides en contraposició. Els informants han definit salut a partir de la negació de malaltia: "no tener ningún tipo de dolencia, ni física ni psíquica, no tener ningún tipo de mal", no com a entitat per ella mateixa. Però la gran majoria dels informants durant l'entrevista han fet varies referències a l'estat psíquic i emocional per definir la salut i la malaltia. Per molts d'ells aquests 


\section{perifèria}

Número 9, desembre 2008

www. periferia. name

aspectes tenen una gran importància i se'ls hi dona un gran valor. La majoria no es van limitar sols a les dolences d'ordre físic, sinó que també hi incloïen aquestes d'ordre psíquic, i tot allò que feia referència al seu voltant.

En el context professional biomèdic es defineix la salut i la malaltia en termes de normalitat/anormalitat, tot allò normal es relaciona amb tenir salut i tot allò anormal amb estar malalt. Canguilhem (1971) defensa que la salut i la malaltia no es poden definir en termes de normalitat o anormalitat, ja que en moltes ocasions el que podria ser normalitat per una persona serà anormalitat per una altra. On comença i on acaba la normalitat/anormalitat dependrà de molts factors; allò que per una persona és un problema greu o urgent, per tant una anormalitat, per una altra allò mateix pot no ésser un problema o en tot cas un problema lleu, és a dir una normalitat. Norma, segons Canguilhem, pot ser tot allò que permet viure. Fora del context professional la dicotomia salut/malaltia es converteix amb bo/dolent, o el bé i el mal. La malaltia se l'ha relacionat amb una cosa dolenta, el mal, per tant una cosa a combatre; la salut amb allò bo, per tant amb el bé. La idea del bé i el mal, bo i dolent, està molt lligada a les grans religions monoteistes, i en el nostre entorn a la cristiana. Són les influències hereves del judeocristianisme que encara perduren avui en molts aspectes de la vida, segons Szasz (1999).

Otegui (2002) senyala 4 grans concepcions de salut: salut/malaltia, la salut com a instrument, la salut com a producte i la salut institucions/medi ambient. La salut/ malaltia és la que hem vist en termes de normalitat/anormalitat. La salut com instrument està molt vinculada al treball manual, i segueix estant present en l'actualitat. La salut, estar fort i valent, és condició necessària per treballar. Per Foucault, el capitalisme va socialitzar la medicina privada d'aleshores, precisament perquè els homes havien d'estar sans per ser rendibles en el treball; va socialitzar el cos en funció de la seva força laboral.

Pues ir a trabajar todos los días sin ningún dolor. El malestar, el no poder ir a trabajar ya me pone enfermo. Yo el fin de semana me da mucha alegría, pero el domingo ya estoy deseando que llegue el lunes, porqué yo en el ámbito que estoy trabajando, una cosa que me gusta, como me gusta, soy el que dirijo, soy el que mando, como no tengo a nadie encima de mí que me mande (...). El no encontrarme bien, el no poder hacer todo esto, el levantarme por la mañana y no poder ir a trabajar ya me pone enfermo. El otro día cuando fui al 


\section{perifèria}

Número 9, desembre 2008

\section{www. periferia.name}

Taulí pensar que al día siguiente no podría ir a trabajar me ponía más malo. Al final pedí el alta para poder ir a trabajar. ( home de 35 anys)

La concepció de salut producte és la més moderna i està lligada al medi urbà, està vinculada al sistema productiu i la seva finalitat és consumir. Aquesta idea es correspon amb les ideologies del neoliberalisme, que responsabilitzen els subjectes socials del seu destí també en salut. És la persona la que s'ha de cuidar i és responsable del que li pugui passar. Es culpabilitza a la persona individual dels mals que patirà. Se l'inculca el sentiment de vulnerabilitat ${ }^{2}$ i el de responsabilitat individual en la malaltia, aquesta s'ha de resoldre a nivell individual i abans no aparegui. D'aquesta manera són diversos els informants que posen en un lloc destacat fer esports, alguns d'ells principalment homes joves referien que si un dia no en podien fer ho vivien com un trauma. També el prendre complexos vitamínics o fàrmacs preventius, de manera ràpida al més mínim problema, és habitual en moltes persones, generant tot això un negoci a l'alça cada dia més important per les empreses multinacionals farmacèutiques, segons Nichter, (2006); Blech, (2005).

Ui, encontrarme bien, mucho, siempre poder estar riendo es básico, es que es básico además, no es una cosa...no es un tópico, eh, para mí la salud por encima de prácticamente todo, la salud es básica para mí. No ir a trabajar me fastidia mucho y no hacer deporte también, y no salir, evidentemente, los amigos, las fiestas (home de 37 anys).

Seguint a Otegui trobem exemples de la concepció que ell anomena salut institucions/medi ambient. Aquesta concepció considera la salut com un patrimoni col-lectiu: els problemes de salut no són individuals, sinó col-lectius, i les institucions sanitàries són les que els han de gestionar. Amb les informacions que ens van arribant al voltant del canvi climàtic, es fan interpretacions particulars de malalties al voltant d'aquest i ens serveix per explicar experiències subjectives, illness, de malalties causades per aquest motiu:

\footnotetext{
${ }^{2}$ Sentiment de percepció real d'estar exposat a algun patiment o desgràcia.
} 


\section{perifèria}

Número 9, desembre 2008

www. periferia.name

Ahora mismo pienso que el ambiente en si, en la calle, todo esto yo lo noto enrarecido, temperaturas, donde yo trabajo hay unos cambios de temperatura de la calle a dentro, del frío al calor pasas en dos segundos, y esto a mí con lo que he pasado ahora creo que ha sido muy influyente el tema de temperaturas, las temperaturas una causa que influyen mucho. (...) A nivel general el ambiente, la capa de ozono, influyen, influyen, en mi mucho, menos que el trabajo en si (home de 37 anys).

Però percebre o no un bon estat de salut depèn de diversos factors, com pot ser el suport que tinguem, els estats d'ànim o les expectatives de cada moment. De fet, al llarg d'una entrevista, un mateix informant podia definir com a més o menys el grau de salut percebut en funció del que estàvem parlant i per tant de les expectatives que ell posava en allò que dèiem.

Quan no em pugui moure del llit, que estigui fotut, una vida molt sedentària, i el dia que em traguessin massa del menjar, el beure el gotet de vi i aquestes coses diguéssim, prova d'això llavors diria collons si que estàs fotut. (home de 77anys)

A la realitat, en definitiva, sovint tenir salut o malaltia no són dues realitats excloents. Es percep la salut/malaltia com un procés i/o un continu, que formen part de la vida i s'ha d'aprendre a conviure-hi.

La separació entre salut i malaltia és mínima, és una divisió molt petita, una línia molt prima. (dona de 55 anys)

No tots els problemes de salut o malaltia es perceben amb la mateixa intensitat o angoixa; n'hi ha uns que per diferents motius ens preocupen molt més que altres. La malaltia que més preocupa a les persones, sense distincions entre homes o dones, joves o grans, és el càncer. El càncer segueix sent als ulls de les persones una malaltia misteriosa, de la qual no se'n saben bé els orígens i no està resolta ja que no té un tractament eficaç. Com diu Sontag (2003), és un "mal lleig" que és millor no mostrar-lo, per tant, s'ha d'ocultar en la mesura que es pugui. I si és un "mal lleig" és que té alguna cosa de dolent i pervers. Se l'ha dotat de significat moralista, d'enemic diabòlic que el converteix en una malaltia vergonyosa i se'l transforma en metàfora.

La malaltia que més em fa patir és un càncer, és una malaltia que pito, pito, et toca i ja està (dona de 24 anys). 


\section{perifèria}

Número 9, desembre 2008

www. periferia.name

Pero lo que le temo más a la vida creo que es un cáncer, eso es a lo que más le temo. He pasado un tiempo muy malo pensando que tenia uno y bueno gracias a Dios me dijeron que no, que no, que era benigno y tenia niños pequeñitos, yo creo que es a lo que más le temo, a eso (dona de 63 anys).

Al càncer el segueix la preocupació pel dolor, el fet d'haver de suportar un dolor prolongat en el temps espanta a les persones. Una altra preocupació són les malalties que condueixen a una invalidesa. La possibilitat de perdre l'autonomia pròpia i dependre dels altres, tant a nivell físic com psíquic, és motiu de preocupació. Però les pors i preocupacions depenen en part de les experiències viscudes en l'entorn més immediat, si aquestes han estat positives o negatives alleugeriran o augmentaran les pors. Es detecta un alt grau de por i d'angoixa en les persones a patir malalties. He fet una classificació d'aquestes en els següents termes:

- Por a una malaltia coneguda i que es creu que pot portar a la mort

- Por a les malalties invalidants, tant psíquica com físicament, i que poden convertir en éssers dependents dels altres

- Por davant d'una incertesa, davant de qualsevol fet que no es coneix i del qual no se'n sap el final

- Por al dolor

L'estat de salut que percebien els meus informants el vaig comparar dins dels límits possibles amb un estudi de l'ESCA (2002) ${ }^{3}$. Tot i ser dos estudis diferents, I'ESCA és un estudi quantitatiu amb mostra representativa, i en canvi, el meu estudi és qualitatiu, amb mostra no representativa, i realitzat mitjançant entrevistes en profunditat, però crec que permeten certa comparació. Segons I'ESCA, 4 de cada 5 persones perceben la seva salut com a bona, molt bona o excel-lent, és a dir, que només 1 de cada 5 percep l'estat actual de la seva salut com a regular o dolent. En el meu treball he de dir que el gruix que la considera regular i dolenta és bastant més elevat, al voltant de 2 de cada 5 persones; el gruix dels que la perceben bona

\footnotetext{
${ }^{3}$ L'ESCA és una treball realitzat l'any 2002 pel Departament de salut de la Generalitat sobre la salut de la població catalana. Dades de la pàgina web: www.gencat.net/salut/depsan.
} 


\section{perifèria}

Número 9, desembre 2008

www. periferia. name

estaria al voltant de 2 de cada 5, i menys d'1 de cada 5 referien tenir-la molt bona. Per tant els resultats del meu estudi són sensiblement pitjors que en I'ESCA, tot i que vaig tenir en compte que eren efectuats durant el procés d'una malaltia. Això es podria interpretar com que I'ESCA va realitzar el treball mitjançant una enquesta amb resposta ràpida, i el meu treball, al ser una entrevista en profunditat, donava Iloc a moltes matisacions. Per exemple, en relació a l'estrès que patien o a problemes emocionals o d'angoixa derivats del dia a dia, fet que els feia baixar el nivell de salut que en un principi havien referit tenir. En els últims anys del segle XX han augmentat les desigualtats en la salut percebuda a I'Estat Espanyol, segons apunta Gutiérrez-Fisac ${ }^{4}$ (2002). És una dada a tenir en compte, i que també podria tenir relació amb el meu treball respecte de I'ESCA. També en el meu treball he observat una tendència a referir pitjor salut en les dones que els homes, tal com ja apunten autors com Navarro (1996), López-Casanovas (2002) i Borrell et al. (2004) entre molts altres.

En les entrevistes apareix la percepció de vulnerabilitat. La persona per se és un ésser vulnerable (Torralba (1998), però on té la màxima percepció de vulnerabilitat és en la malaltia, perquè sap tot el que comporta de dolor i de patiment, i també perquè pot portar fins al final de tot: la mort. La vulnerabilitat de la persona es pot veure en les entrevistes; hi ha la consciència que som fràgils, i això comporta un patiment afegit a la realitat de la malaltia. I la percepció de vulnerabilitat va més enllà de l' estrictament personal, s'amplia a l'àmbit domèstic, s'és conscient de la seva fragilitat, està exposada a múltiples riscos que la poden destruir fàcilment:

Sí, pero no por mí, sino por lo que tengo detrás, tengo a mi marido, que cuando yo me pongo enferma se le cae el mundo encima, luego tengo unos hijos que los pobres sufren bastante con que su madre esté enferma. Luego están mis nietos, la necesidad que ellos tienen de tener la abuela, no es otra cosa porque la vida sigue. Si tú faltas todo el mundo se arregla como puede, y sigue, la vida sigue. Pero a veces piensas si a mí me pasa algo todo se va al carajo. El motor de la casa yo creo que es la mujer, una mujer y una madre. Yo creo que sí, que eso une muchísimo, para mí (dona de 63 anys).

\footnotetext{
${ }^{4}$ Gutiérrez-Fisac, JL. (2002). Desigualdades sociales en la salud subjetiva y en varios trastornos crónicos de salud en España. En: RondaE. Editora Desigualdades sociales en salud: Situación en España en los últimos años del siglo XX. Cocentaina: Universidad de Alicante. Sede Universitària de Cocentaina. Citat a Borrell et al. (2004).
} 


\section{perifèria}

Número 9, desembre 2008

www. periferia. name

Aquest sentiment de vulnerabilitat es fa més evident i visible en les classes socials més desafavorides, que tenen menys recursos econòmics per solucionar qualsevol problema que sorgeixi.

Un altre sentiment important en la persona és el de seguretat. I en aquest hi contribueix molt directament la comunicació i la informació que es pugui rebre, principalment davant de processos que comporten fragilitat com la malaltia. Varen ser bastants els informants que referien no estar satisfets amb la informació que els donaven els professionals sanitaris, fet que els havia portat a fer una nova consulta en un temps més curt. Existeixen molts estudis, entre els quals Busquets (2006) que posen de manifest la gran importància que té una bona informació en els problemes de malaltia.

\section{Causes i creences al voltant de la salut i la malaltia}

Les persones no creuen que tinguin els suficients coneixements per contribuir a les seves cures en la malaltia. Tot allò que fa referència a la malaltia ha passat a formar part del camp professional, per tant, ens cal aquest professional per resoldre qualsevol problema que ens aparegui. Seguint a Comelles (1993), a partir del segle XVIII es va iniciar l'apoderament de tots els saber populars sobre medicines, es van anar ridiculitzant els coneixements i les pràctiques consuetudinàries domèstiques en la salut, fins a estar totalment professionalitzats. Al formar part del camp professional ens cal el professional per resoldre qualsevol problema que ens aparegui, i aquesta tendència ha augmentat de manera molt més important en els últims decennis, tal com ja he esmentat abans, coincidint amb la tecnificació de la biomedicina. En un estudi de l'any $1972^{5}$ a Anglaterra, Dunnell i Cartwrigt constataven que davant la presència de símptomes anormals només el $16 \%$ dels entrevistats referia haver anat al metge abans de dues setmanes de la seva aparició. En la mateixa línia es van manifestar els meus informants de més edat. Eren explícits en aquest sentit: de joves ben poques vegades anaven al metge, en canvi ells mateixos en els últims anys reconeixien que fins i tot per una

\footnotetext{
${ }^{5}$ Dunnell, K. and Cartwrigt, A. (1972) Medicine Takers, prescribers and Hoarders. Routledge and Kegan Paul. Citat a Helman, Cecil (2002)
} 


\section{perifèria}

Número 9, desembre 2008

www.periferia.name

grip o un refredat el consultaven de manera ràpida. I si no era per iniciativa pròpia, ho era per la d'un familiar directe.

En relació a allò que les persones creuen que és el causant de la seva salut o les malalties, hi ha una forta influència del sistema biomèdic en el sentit de pensar que les malalties tenen origen per un desordre del propi cos, físic o degudes a comportaments nostres -que podríem evitar si volguéssim-. D’aquesta manera s'estigmatitza a les persones que pateixen problemes derivats de la ingesta de l'alcohol i de les drogues, i en menor mesura del tabac, ja que se les considera que són les úniques culpables dels seus mals:

N'hi ha que cauen perquè s'ho busquen eh, els uns perquè s'emborratxen, els altres perquè es droguen, hi ha molta gent malalta perquè s'ho busca, jo a aquests no els perdono, ara lo que jo he agafat no ha sigut cap cosa d'aquestes, entonces sí que considero que és una malaltia que agafem les persones (home de 79 anys).

El fet de culpabilitzar a les persones i estigmatitzar-les per les seves addiccions és també molt estès entre els professionals sanitaris, i com molt bé ens diu Menéndez (1991) aquí els factors socials hi juguen un paper molt important i cabdal. Poques persones fan una acció que vagi en contra de la seva vida, sovint s'hi veuen empesos per les circumstàncies del seu entorn que els són extremadament contràries i desfavorables.

En relació a l'alimentació - un aspecte que ha sortit en la majoria d'entrevistes- la majoria de persones refereixen tenir els suficients coneixements per poder portar una vida més sana però no sempre els apliquen; en aquest sentit hi ha poca sensació de culpabilitat, s'arregla sovint dient: "d'alguna cosa hem de morir".

Yo en mi caso de saber si que lo sé, otra cosa es que lo haga, una persona que haya vivido un poco y visto reportajes sabe cuidarse un poco, otra cosa es que lo hagas. Porque te pasas con la comida, porque te gusta, con la bebida, o fumas, son vicios. Todo el mundo se asea, todo el mundo más o menos comer bien, hoy todo el mundo sabe lo que tiene que comer, no es como antes que todo era tocino, grasa y... yo en mi caso con la comida me cuido mucho, lo que pasa que tenía que haber empezado hace 30 años, no ahora (home de 53 anys). 


\section{perifèria}

Número 9, desembre 2008

www.periferia. name

Però a la vegada que hi ha aquesta influència tan forta de la biomedicina - de unicausalitat de les malalties-, també trobem moltes persones que creuen que els seus problemes de salut tenen uns orígens que es produeixen molt més enllà del seu cos o de la seva estricta responsabilitat. Són vàries les persones que estan convençudes que els problemes derivats de la feina, de les dures condicions de vida que els ha tocat viure o de les actuals condicions de vida tenen molt a veure amb el que els està passant en l'actualitat.

Marmot i Wilkinson (2006) van anomenar "solid facts" o "fets irrefutables" als 10 factors que influien més en la salut de la població. Alguns informants són conscients que la seva salut està fortament condicionada per factors socials i econòmics:

Pues la causa mía el estrés que llevaba, llevaba mucho estrés, yo creo que mi enfermedad ha venido de eso, del estrés que llevaba. Pues sí, el tener unos padres mayores, estar enfermos ellos y yo tener 4 hijos, pues claro que tenía una jornada grande, y es esto lo que a mí me ha ido afectando la salud. Yo creo que ha sido esto, además yo trabajaba un poquito y todavía voy haciendo, y cosas que ya vienen, enfermedades que vienen, cosas que te van afectando todo. Yo creo que ha sido todo esto, el conjunto de cosas lo que ha hecho mi enfermedad. Has tenido que cuidar unos padres 20 años enfermos, cuando no tenían una cosa tenían otra, y tú tenías que llevar tus hijos y tu esposo a la carga, porque claro, él también estaba enfermo. Pues todo eso yo creo que me ha ido afectando bastante, eh. Para mí una de las cosas que veo es que he tenido mucha, mucha faena que llevar, mucho estrés, sobre mis espaldas, y entonces... eso me afectó mucho, mucho (dona de 62 anys).

\footnotetext{
${ }^{6}$ Els 10 "Solid Facts" que més incideixen en millorar o que ajuden a patir més problemes de salut són els següents: 1-el pendent social, les persones que estan en els estrats socials més baixos, tenen el doble de risc de patir malalties greus i mort prematura. 2-L'estrès, els estats d'ansietat, inseguretat, baixa autoestima o aïllament social. 3-els primers anys de vida són decisius per la salut al llarg de la vida. 4l'exclusió social, la privació material i els problemes socials i psicològics de viure en la pobresa. 5-el treball, les persones que tenen més control sobre el seu treball estan més sanes; poc control comporta més risc de malaltia. 6-l'atur, els problemes materials, financers i psicològics comporten més malalties i mort. 7-el suport social, l'amistat, les bones relacions socials i unes sòlides xarxes de suport milloren la salut. 8-les addiccions a drogues o alcohol contribueixen a potenciar les desigualtats en salut $\mathrm{i}$ a patir més malalties i mort prematura. 9-els aliments, l'escassetat i la no varietat contribueixen negativament. 10-el transport, caminar més i utilitzar menys el transport contribuiria a millorar la salut.
} 


\section{perifèria}

Número 9, desembre 2008

www. periferia.name

La tensión que tenía, hace poco vino una inspectora a evaluarme el centro, el colegio, donde trabajo, y el estrés y la tensión me produjeron el problema. Venían a evaluarme y lo tenía que tener todo preparado, eso y el viaje de vacaciones en Italia, el clima que no acompañó mucho, el frío que cogí, son muchas variantes. Yo lo relaciono con esto. Sí, lo situaría en ese momento, el estrés y todos los nervios que pasé, yo soy una persona que me lo voy guardando, después la tensión se acumula y sale por algún lugar, a mí me afectó a las cervicales, tengo la espalda resentida (home de 30 anys).

Un poco la vida ajetreada, el estrés, el trabajo, todo muy rápido, muchos ruidos, muchas obras, mucha gente, vas a un centro comercial mucha gente, todas esas cosas así, a mí también me agobian un poquillo (home de 30 anys).

$\mathrm{Hi}$ ha creences en uns altres tipus de malalties que sovint no es tenen en compte, pensem que enmig de l'era tecnològica ja no existeixen, però que sí que encara segueixen existint: són les creences en malalties com el mal d'ull. Baer et al. (2006) van realitzar un estudi a la província de Huelva en el qual posaven de manifest que aquestes creences a l'actualitat encara hi són ben presents. En el meu treball pràcticament el $80 \%$ de les persones que vaig entrevistar hi creien, elles mateixes o algú del seu entorn, i a més havien portat a terme pràctiques per la seva curació. Sols al voltant del $20 \%$ van referir que elles no hi havien tingut cap relació ni conèixer algú que ho hagués fet. Coincideixo amb Baer et al. que els nens són el grup més susceptible de patir mal d'ull.

\section{Les pràctiques i recorreguts o passos que es realitzen davant la malaltia}

El que decidim fer davant d'un problema de salut que ens apareix té relació directa amb la sensació de gravetat i d'urgència que percebem del problema. Es decideix de fer una cosa o una altra davant d'aquesta percepció. Però el que signifiquen aquests dos conceptes no és compartit pels professionals sanitaris i els usuaris. La biomedicina entén la urgència i la gravetat en funció de "la descompensación fisiològica i/o pèrdua de funció orgànica, amb probabilitat de mort" segons apunta Gómez Jiménez (2006). La OMS va efectuar la següent definició sobre el concepte d'urgència: 


\section{perifèria}

Número 9, desembre 2008

www. periferia.name

La aparición fortuita (imprevista o inesperada) en cualquier lugar o actividad, de un problema de salud de causa diversa y gravedad variable, que genera la conciencia de una necesidad inminente de atención por parte del sujeto que lo sufre o de su familia (citat a Gómez Jiménez,2006: 156).

Però aquesta definició no explica què vol dir gravetat variable o necessitat imminent d'atenció, i aquests aspectes poden ser diferents per cada persona. En canvi, les persones sovint per definir urgència i gravetat tenen més en compte altres factors que s'allunyen molt dels establerts per la biomedicina.

Les idees del concepte de gravetat que han manifestat els informants les he agrupat en quatre punts, que no són excloents i cada informant en pot ressaltar un o més:

- Un fet que provoca la sensació que repercuteix seriosament en la vida i salut de la persona, també tenir la sensació d'haver-se de morir, o creure que un problema pot tenir una solució difícil.

- El fet d'aparèixer una cosa desconeguda per nosaltres, una cosa que abans mai havíem tingut i no la coneixíem, ni per experiència pròpia ni per persones properes. La seva aparició crea inquietud i incertesa davant el què ens pot esdevenir, apareix la por i fa que les persones se sentin més vulnerables.

- Un fet ja conegut, que pot ser una cosa relacionada amb altres experiències pròpies, que ja ens hagin passat anteriorment o que les coneguem perquè les hagin viscut persones del nostre voltant. Sabem que són potencialment perilloses, perquè poden comprometre seriosament la salut o la vida de les persones.

- Per últim, el fet de no poder fer una vida normal, que aparegui un impediment de manera més o menys sobtada, és motiu de percepció de gravetat per algunes persones. Aquests casos eren bàsicament d'homes joves o de mitjana edat que li donaven molta importància a fer, per exemple, esport o sortir amb amics. 


\section{perifèria}

Número 9, desembre 2008

www. periferia. name

En relació al concepte d'urgència manifestada pels meus informants, també l'he agrupat en quatre punts, i de la mateixa manera que la gravetat, no són excloents i cada informant també en pot ressaltar un o més:

- Lligada al dolor; una sensació molt desagradable que tu sents, que et causa malestar i que no pots esperar més a tractar-la, i necessites rebre ajuda sanitària de manera immediata. Encara que donessin una altra definició d'urgència, en la majoria d'informants també apareixia el dolor.

- El no coneixement sobre un problema de salut que ens apareix. Que sigui una cosa desconeguda per nosaltres o per les persones del nostre entorn; això crea una incertesa que porta a la demanda d'assistència.

- També es considera urgència si se'ns presenta un problema que tingui a veure amb una experiència ja coneguda per la mateixa persona o per les del seu voltant, sent una experiència que hagi precisat atenció mèdica i/o hagi estat viscuda com a problema anteriorment.

- Per últim, els accidents són de les causes que bastants dels entrevistats van relacionar més amb anar a urgències, però per a cap d'ells no va ser el motiu de la consulta que havien fet en aquell moment, i per la qual jo els estava entrevistant. Possiblement tingui a veure o estigui influenciat per les sèries de televisió sobre hospitals; doncs en aquestes sí que hi apareixen bastants accidents - molt espectaculars alguns- i alguns informants hi van fer referència al parlar de les sèries televisives.

Segons em relatava un informant, "greu" i "urgent" era no poder anar a treballar perquè ell era, gairebé, l'única font d'ingressos d'una llar extensa ja bastant castigada per problemàtiques d'índole social. Un altre considerava greu un problema que no el deixés fer vida social o esports. La percepció d'urgència i gravetat davant d'un problema comporta: preocupació, angoixa, incertesa i por. Aspectes que no es contemplen des de la biomedicina. Existeix, per tant, una dissociació entre el que entén per gravetat i urgència la biomedicina i els usuaris. Per aquest camí, sense tenir en compte a la globalitat de la persona, és difícil de poder donar solució al problema de les urgències. 


\section{perifèria}

Número 9, desembre 2008

www.periferia. name

Si no es percep gravetat o urgència se seguiran uns passos diferents de si aquests es perceben. Però per un mateix procés de malaltia molt sovint es realitzen varis recorreguts. Els "Pathways Models" estudien els diferents passos i camins en el procés assistencial, però com apunten Hausmann-Muela et al. (2003), s'ha investigat fins al primer contacte, mentre que els següents no estan pràcticament estudiats.

A partir de les informacions que m'han facilitat les entrevistes realitzades $i$ de les conversacions a les sales d'espera d'urgències he agrupat els passos del procés assistencial en els següents punts:

- Autoatenció o sector popular. Aquí les cures corren a càrrec d'un mateix, i/o es demana consell a un familiar, o a una persona coneguda, sigui un amic, veí o company de treball. Inclou els coneixements anomenats tradicionals i la automedicació.

- Anar a la farmàcia a comprar medicació sense recepta, sigui ja coneguda o que sigui el farmacèutic que la aconselli.

- La visita al metge de capçalera.

- La visita a urgències de I'hospital

- La visita a un metge especialista, enviat pel metge de capçalera o de manera privada.

- L'ús de les medicines alternatives o complementàries.

Aquests passos o recorreguts no sempre segueixen aquest mateix ordre, tot i que ho facin sovint. Però al llarg d'un procés, si la seva durada es dilata molt en el temps, es poden anar efectuant recorreguts i les anades i vingudes entre uns passos i altres sovint són una constant. Si el problema és de durada curta i de poca complexitat es realitzen pocs passos, però si no és així se'n poden efectuar molts. Algunes persones, degut al procés pel qual els vaig entrevistar, i que havia tingut inici feia poc temps, ja en portaven 6 o 7 i el procés encara no havia finalitzat. 


\section{perifèria}

Número 9, desembre 2008

www. periferia. name

En els recorreguts hi entren en joc varis models mèdics ${ }^{7}$. Menéndez (2005) els divideix en: model de l'autoatenció, model mèdic alternatiu subordinat i model mèdic hegemònic. Kleinman (1980) els divideix en: sector popular, sector folk $\mathrm{i}$ sector professional. I com hem vist anteriorment, els tres sectors entren en joc en el recorregut assistencial, estan interconnectats, les persones van i venen d'un a l'altre.

Els remeis casolans -com la llimona, la mel, soles o amb llet, la llet amb mel i conyac- i els productes d'herbolari són utilitzats pel voltant del $70 \%$ dels entrevistats de manera més o menys habitual. Les indústries farmacèutiques, en veure que cada vegada més persones es decanten pels productes d'herbolari i remeis naturals, n'han potenciat més el seu ús pel gran negoci que els suposa aquest camp, segons Menéndez (2005).

En relació a les medicines complementàries i/o alternatives, (TCA) com I'homeopatia, l'acupuntura, el naturisme o la quiropràctica, en el nostre país la seva introducció és molt més recent que en altres països europeus, com per exemple la Gran Bretanya. Però la seva utilització ha anat en augment en els últims anys, i al voltant del 35\% dels entrevistats les ha utilitzat alguna vegada. Segons ÁlvarezHernández (2006), s'ha notat un augment considerable en el seu ús quan es tracta de malalties cròniques com les reumàtiques o la fibromiàlgia, entre d'altres.

\section{Els centres d'atenció primària i els serveis d'urgències hospitalaris}

Els centres d'atenció primària (CAPs) han estat pensats per ser el primer esglaó en l'assistència sanitària, per ser el lloc més proper al ciutadà i en el qual existeixi complicitat entre aquest i el professional. Però sembla que alguna cosa no acaba de funcionar, ja que sovint els ciutadans se salten aquest esglaó i van en busca d'un altre quan ells creuen que tenen un problema seriós. La majoria de ciutadans refereixen tenir confiança en el seu equip d'atenció primària. El metge, per molts

\footnotetext{
7 (...) aquellas construcciones que a partir de determinados rasgos estructurales suponen en la construcción de los mismos no sólo la producción teórica, técnica, ideológica i socioeconómica de los "curadores" (incluidos los médicos), sino también la participación en todas esas dimensiones de los conjuntos sociales implicados en su funcionamiento. (Menéndez, 1983:4) Citat a Barragan 2005: 66)
} 


\section{perifèria}

Número 9, desembre 2008

www.periferia.name

d'ells, diuen que és una persona propera i coneguda, a la que valoren positivament, també coneixen a la infermera, sobretot les persones d'edat avançada o amb problemes crònics de salut, pel què han d'anar sovint a realitzar-se controls. Els CAPs són vistos com a centres més de control, per anar a buscar les receptes, i no pas allà on veritablement et poden solucionar un problema de salut quan apareix. La majoria d'informants valorarien molt millor el CAP si aquets disposés de tecnologies que els permetés la realització de proves, veuen un desavantatge important el no disposar-ne, ja que es considera que són necessàries per un bon diagnòstic i poder-se curar abans.

En l'era tecnològica a poc a poc els hospitals s'han convertit en santuaris, són els nous "santuaris de la ciència moderna" en el camp de la ciència i de la medicina i que ens informen i recorden cada dia els mitjans d'informació, junt amb les sèries televisives ${ }^{9}$ principalment sobre els serveis d'urgències, han ajudat a posar les expectatives de les persones vers aquests llocs en una posició molt elevada. Els hospitals són aquell lloc on es creu que tot és possible, on s'hi fan gairebé miracles, on ens donaran les solucions per tot:

Ventajas porque te encuentras muy, o sea yo cuando entro por allí ya estoy, o sea tengo la sensación que estoy en el sitio adecuado, que allí te hacen de todo de lo que tengas, allí te saben de todo, te hacen todas las pruebas, y todo, tanto los médicos, como los camilleros, como las enfermeras como todo, todo lo del Taulí es gente muy capacitada, muy preparada, yo a veces pienso como no se harán un lío con tanta gente y con tanta cosa, yo los veo muy capacitados (home de 60 anys).

En ser preguntades les persones pels avantatges en la utilització del servei d'urgències de l'hospital, sense cap mena de dubte la resposta era per les proves diagnòstiques que se'ls realitzava: radiografies, analítiques, TAC, i tot allò que pugui ser necessari. No es concep que es pugui diagnosticar bé, amb seguretat, una malaltia sense la realització de proves diagnòstiques. A més, anar a urgències de l'hospital evita pèrdues de temps en dos sentits: se sap més aviat el diagnòstic -

\footnotetext{
${ }^{8}$ En termes de Konner "Temple of Science". Konner, M. (1993) The Trouble with Medicine, pp.. 22-47. BBC Books. Citat a Helman 2002: 64.

9 Les organitzacions mèdiques i el Col-legi de Metges han denunciat vàries vegades les falses expectatives que es generen a partir d'aquestes sèries.
} 


\section{perifèria}

Número 9, desembre 2008

www. periferia.name

- degut a la rapidesa de la tècnica- i això evita a les persones angoixes i pors davant allò incert i que preocupa; i en el temps material en sí, per no haver de demanar permisos a la feina -encara que hagin d'esperar unes hores, sortir tenintho tot fet és un avantatge-.

Hoy con los aparatos que hay, con los aparatos que tienen, con la técnica esa, creo que ayudan bastante, yo creo que dan rápidamente con la verdad si se dedican a buscarla (home de 63 anys).

Si no me lo hubieran hecho hubiera pensado que el profesional era listísimo... que me lo había detectado a la primera o que urgencias no se si tiene la fama o que de saturación, porque la verdad que había bastante saturación, allí estuve unas $6 \mathrm{~h}$. por lo menos. Si no me hubieran hecho a lo mejor hubiera pensado esos se quieren sacar la estadística para acabar rápido, pero si, si me las hicieron (home de 43 anys).

I un altre avantatge que s'apunta d'anar a urgències de l'hospital és l'experiència dels professionals. Es veu als professionals de l'hospital millor preparats, en general, que a l'atenció primària, pel fet de veure més vegades la mateixa cosa. En relació als desavantatges, s'anomena bàsicament les hores d'espera, és el que més citen els usuaris.

Però a la vegada que es manifestava un desig i/o una necessitat que realitzessin proves diagnòstiques per tenir una millor seguretat sobre allò que et passava, també en totes les entrevistes en un moment o altre aflorava la falta d'empatia entre els usuaris $\mathrm{i}$ el personal sanitari. Molts d'ells trobaven uns professionals allunyats i distants que no satisfeien les seves preocupacions. La informació que reben sovint no s'acaba d'entendre i no resol tots els seus dubtes. Aquest motiu els feia realitzar una altra consulta mèdica, que no haguessin efectuat si se'ls hagués donat una millor informació que els hagués deixat més convençuts i amb més tranquil·litat, segons manifestaven ells mateixos. 


\section{perifèria}

Número 9, desembre 2008

www. periferia. name

Hi ha professionals que t'ho expliquen d'una manera adequada que no t'afecti psicològicament el problema que tens, i hi ha persones que t'ho diuen i si et sent bé be, i sinó també. Una persona que et digui hi ha això i ja està ja pots marxar, no t'expliqui bé et crea desconfiança, no li tinc gens de confiança no m'agrada que em tractin així, que em diguin les coses d'aquesta manera, m'agrada més que m'expliquin el que tinc, es una cosa que nosaltres desconeixem, perquè a tu quan et diuen que tens una lesió tu no coneixes els ossos, no coneixes l'esquena, no coneixes els problemes que pots tenir, les infeccions, etc, no? per això està la persona, el professional que t'ho ha d'explicar, i si és una persona que t'ho diu així de clar i no t'explica res mes no et crea confiança, et crea confiança una persona que t'ho explica i que et dona confiança (dona de 24 anys).

L'estada al servei d'urgències des del punt de vista antropològic pot ser vista com una representació del ritual, i en especial del "ritual de pas" de Van Gennep. La majoria d'informants descrivien clarament les tres fases dels "rituals de pas": el període de separació que és el que es passa a les sales d'espera esperant ser visitat; el liminar és el de la visita mèdica, quan s'està a dins el servei per fer-se tot allò que calgui, aquí el temps no importa gaire, és per això que has vingut, perquè se't realitzin totes aquelles proves que siguin necessàries; i finalment la fase de reintegració o agregació una altra vegada al món dels bons.

Les teories de contaminació de Mary Douglas (1966) també hi són presents. Davant de la visió de desordre que una informant creia que hi havia en el servei, ella va voler organitzar i posar ordre en el seu propi espai, en vistes a la nit que havia de passar en aquell entorn. Existeix la necessitat de marcar fronteres i ordre per evitar la contaminació, és a dir, el desordre. Aquest s'associa a la brutícia; I'ordre, a la netedat.

Ja des de l'inici de les entrevistes i també en les sales d'espera es va fer evident i va ser una constant la referència "als altres". Aquests "altres" se'ls considera menys mereixedors d'assistència sanitària que "nosaltres". Davant d'uns recursos que es perceben escassos no s'està disposat a compartir-los amb unes persones que se les creu menys mereixedores de rebre'ls. Aquests "altres" són: les persones immigrades, els gitanos i les persones amb drogoaddiccions. El col-lectiu immigrant és el més nombrós i més visible, per tant, el més potencial consumidor de recursos dels tres grups. S'erigeix així a ulls de la població del país com un fort competidor 


\section{perifèria}

Número 9, desembre 2008

www.periferia.name

per uns recursos que en alguns moments es perceben i viuen com escassos.

Això que vinguin tants immigrants que tenen tot el dret i que nosaltres hem de pagar tants milions a la seguretat social i que ara estem mal servits també en part pels cales que se'n van, i llavors venen aquí i et fan mal, roben, atraquen, maten, violen, i el seu país allà, que ells ens envien tota l'escòria casi, pobre gent, prouta pena tenen a ser així, pro collons, ho visc d'aquesta manera. (...) hi havia un noi drogoaddicte allà a la nostra vora que van haver de córrer tots perquè aquell noi no sé pas que. I atents com una mala cosa, com si hagués sigut el bisbe, amb aquest xicot, el van atendre bé, amb un carinyo, amb un carinyo, com que no entenia cap idioma, que hablas castellano? Era romanès, no sabia res (home de 77 anys).

Había unos negros con las piernas así tiradas, allí durmiendo a por el papel, una mora con dos o tres niños a por otro papel que iba resfriada, pues vete al ambulatorio hombre. Allí hay que ir por otras cosas. Hombre, todos esos que vienen de esos países, hacen un gasto grandioso, no digo que no haya que atenderlos, yo no soy racista, pero eso no puede ser. Le falta una atención grandísima i que se den cuenta que esto que han hecho es tremendo, es tremendo, porque unos derechos que teníamos nosotros, de todas las personas que hemos trabajado aquí desde que vinimos con 22 años, y que ahora vayas a unas urgencias y que no te puedan atender porque no hay médicos. Porque ya digo la que me atendió no era de aquí, y jovencísima, esa mujer qué rodaje puede tener. Así no dieron conmigo, claro, cómo van a dar (dona de 73 anys).

Dels gitanos està més acceptada la seva assistència sanitària. S'està més acostumat a la seva presència, ja que des de fa molts anys conviuen entre nosaltres i, a més, és un grup molt menys nombrós que els immigrants. Però el que no se'ls tolera, de cap manera, és el seu tarannà.

Pel que fa a les persones drogoaddictes, se les ha estigmatitzat, es creu que si tenen una drogoaddicció és perquè no han fet res per evitar-ho, per tant tampoc s'està disposat a destinar-hi gaires recursos.

Bueno, és que és una opinió una mica forta, bueno jo penso que per exemple una persona que és drogoaddicta (és des del meu punt de vista, cuidado) és drogoaddicte perquè vol, ella s'ha ficat dins aquest problema, penso que subministrar-li metadona per mi està molt mal fet (dona de 43 anys).

Aquí les teories de Teresa San Román (1996) sobre marginació i racisme prenen tot el seu valor. S'exclou als "altres" d'allò que creiem que ens pertany sols a "nosaltres". En tot cas s'estaria disposat a donar-los una part petita, les sobres, però no la mateixa proporció que creiem que ens pertany. 


\section{perifèria}

Número 9, desembre 2008

www. periferia.name

Els percentatge de ciutadans estrangers que residien a Sabadell ${ }^{10}$ l'any 2006 era del $\mathbf{9 , 6 6 \%}$. De les assistències realitzades, també a l'any 2006, en el servei d'urgències de l'Hospital de Sabadell ${ }^{11}$ el 7,9\% corresponia a ciutadans estrangers. Tot això tenint en compte que possiblement la població immigrada real sigui més elevada del que diuen les dades oficials, que alguns organismes xifren al voltant del 14-15\%. Segons aquestes dades, el col-lapse en el servei d'urgències no vindria provocat per l'atenció a aquestes persones.

\section{Conclusions}

La salut és percebuda com el bé més preuat i important, allò que ens permet portar el ritme de vida que se'ns imposa i de manera autònoma. Per tant, en el més mínim problema de salut que ens aparegui, tendirem a creure que tenim una necessitat imminent de tractament, fet que fa augmentar la demanda d'assistència sanitària i la utilització, sense límit, de totes les tecnologies que tenim al nostre abast. Això passa perquè es tendeixen a percebre com a greus i urgents molts d'aquests problemes que tenen el seu origen en aquesta necessitat percebuda. Però a la vegada existeix una demanda molt important d'atenció més humana i centrada en la persona, de parar-nos a parlar i poder expressar els nostres sentiments, les angoixes i les pors.

\section{Bibliografia}

Ajuntament de Sabadell [en línia] http://www.ajuntamentdesabadell.cat [consultat el dia10-4-08]

Álvarez-Hernández, E.; Casasola-Vargas, J.C.; Lino-Pérez, L.; Burgos-Vargas, R.; Vázquez-Mellado, J. (2006). Frecuencia de uso de medicinas complementarias y alternativas en sujetos que acuden por primera vez al servicio de reumatología. Análisis de 800 casos. Reumatologia Clínica: 2(4): 183-9.

Aranaz Andrés, Jesús M. et al (2006). ¿Por qué los pacientes utilizan los servicios de urgencias hospitalarias por iniciativa propia. Gaceta Sanitaria, 20(4):311-5.

\footnotetext{
${ }^{10}$ Dades de la pàgina web de I'Ajuntament de Sabadell: www.sabadell.cat

${ }^{11}$ Dades facilitades per la Unitat de la Organització de la Informació Assistencial, CSPT.
} 


\section{perifèria}

Número 9, desembre 2008

www. periferia.name

Augé Marc \& Herzlich, Claudine (1995) [1983]. The Meaning of Illness. Hardwood Academic Publishers. Luxemburg.

Baer, Roberta C. Weller, Susan C. Gonzales Faraco, Juan Carlos; Feria Martín Josefa. (2006). Las enfermedades populares en la cultura española actual: un estudio comparado sobre el mal de ojo. Revista de Dialectología y Tradiciones Populares. Enero-junio. Vol LXI, no 1, págs. 139-156.

Benach, Joan; Muntaner, Carles. (2005). Aprender a mirar la salud. Cómo la desigualdad social daña nuestra salud. El Viejo Topo. Barcelona.

Blech, Jörg (2005) [2003]. Los inventores de enfermedades. Cómo nos convierten en pacientes. Ediciones Destino. Barcelona.

Borrell, Carme, García Calvente, María del mar, Martí-Boscà, José V.(2004). La salud pública desde la perspectiva de género y clase social. Gaceta Sanitària 2004; 18 (Supl 1):2-6.

Busquets, Montserrat; Caïs, Jordi (2006). Información sanitaria y La participación activa de los usuarios. Fundació Grifols. Barcelona.

Canguilhem, Georges (1971) [1966]. Lo normal y lo patológico. Siglo XXI. Buenos Aires.

Comellas, Josep Mạ; Martínez Hernáez, Ángel (1993). Enfermedad, Cultura Y Sociedad. Eudema, S.A. Madrid.

CSPT- Àrea sanitària de referència [en línia]

<http://www.tauli.cat/tauli/cat/default.htm. > [Consultada el 8-06-2008]

Douglas, Mary. (1973) [1966]. Pureza y peligro. Siglo veintiuno editores, S.A. Madrid.

Goffman, Erwing (2006) [1963]. Estigma. La identidad deteriorada. Amorrortu. Editores

Gómez Jiménez J, Becerra O, Boneu F, Burgués LL, Pàmies S. (2006). Análisis de la casuística de los pacientes derivables desde urgencias a atención primaria. Gaceta Sanitária, 20 (1): 40-6.

Hausmann-Muela S, Muela Ribera J, Nyamongo I, (2003). "Health-seeking behaviour and the health system response". DCPP Working. Paper N. 14

Helman, Cecil G. (2001) [1984]. Culture, Health and Illness. Editorial Arnold. London.

Le Breton, david (1999) [1995]. Antropología del dolor. Seix Barral Barcelona

López-Casanoves, Guillem; Rivera, Berta (2002). las políticas de equidad en salud y las relaciones entre renda y salud. Hacienda Pública española/Revista de Economía pública. 161, : 99-126.

Lupton, Deborah (1995). Medicine as Culture. Illness, disease and the body in weatern societies. Sage Publications, London 


\section{perifèria}

Número 9, desembre 2008

www. periferia. name

Marmot M., Wilkinson R. G. 82006) [1998]. Social Determinants of Health Oxford University Press.

Márquez, Soledad, Meneu, Ricard (2003). La medicalización de la vida y sus protagonistas. Gestión Clínica y sanitaria. Vol 5; 2: 47-53.

Martínez Hernáez, Ángel (2008). Antropología médica. Teorías sobre la cultura, el poder y la enfermedad. Ed. Anthropos. Rubí (Barcelona).

Menéndez, Eduardo (2005). Intencionalidad, experiencia i función: la articulación de los saberes médicos. Revista de Antropologia Social. 14.33-69.

Menéndez Eduardo L. (1991) Antropología del alcoholismo en México. Los límites culturales de la economía política 1930-1970. Ciesas. Ediciones de la casa chata. México.

Muela Ribera, Joan (2007). Malaria en lipangalala. Pluralismo médico y processos assistenciales para malaria infantil en una comunidad Africana. Departament d'Antropologia Social i Cultural. UAB. Bellaterra. Tesi Doctoral.

Navarro, Vicenç, Benach, Joan (1996) Las desigualdades sociales de salud en España. Rev. Esp. Salud Pública: 70:505-636.

Nichter, Mark (2006). Reducción del daño: una preocupación central para la antropología médica) Desacatos (20) . Pàg. 109-132.

Ochoa Gómez, Javier et al.(2000) Visitas inapropiadas al servicio de urgencias de un hospital general. Medicina Clínica, Vol.115 N.10.

Otegui Pascual, Rosario (2002). Modelos de participación y concepciones de salud de los ciudadanos. Revista de Trabajo social y Salud: 4:33-41.

San Román, Teresa (1996). Los muros de la separación. Ensayo sobre alterofobia y filantropía. Ed Tecnos. UAB. Bellaterra.

San Román, Teresa (1998) [1994] La diferència inquietant. Velles i noves estratègies dels gitanos. Ed. Alta Fulla. Barcelona.

Sontag, Susan (2003([1977] La enfermedad y sus metáforas. El sida y sus metáforas. Ed. Punto de lectura. Madrid.

Stainton Rogers, Wendy (1991). Explaining health and illness. An exploration of diversity. Harvester-Wheatsheaf. Great Britain.

Szasz, Thomas (1999) [1961]. El mito de la enfermedad mental. Círculo de Lectores. Barcelona. 